\title{
Apresentação - Desigualdades, deslocamentos: clínica e políticas na imigração e refúgio
}

\author{
Miriam Debieux Rosa ${ }^{a, b}$ * \\ Sandra Luzia Alencar ${ }^{b, c}$ \\ Taeco Toma Carignato ${ }^{a, b}$ \\ llana Mountian ${ }^{\mathrm{a}, \mathrm{d}}$ \\ aUniversidade de São Paulo, Instituto de Psicologia, Departamento de Psicologia Clínica. São Paulo, SP, Brasil \\ ${ }^{b}$ Pontifícia Universidade Católica de São Paulo (PUC-SP), Núcleo Psicanálise e Política. São Paulo, SP, Brasil \\ 'Secretaria Municipal de Saúde de São Paulo. São Paulo, SP, Brasil \\ ${ }^{d}$ Manchester Metropolitan University. Manchester, Reino Unido
}

O número temático que ora publicamos será comemorativo dos 10 anos de intervenções psicanalíticas e da produção teórica clínica-política desenvolvidas pelo Laboratório Psicanálise e Sociedade no Instituto de Psicologia da Universidade de São Paulo sobre imigrantes e refugiados. No tripé que caracteriza a Universidade, trabalhamos no cruzamento extensão, ensino e construção de conhecimento.

Temos desenvolvido atividades de extensão universitária realizadas por meio de projetos na temática da imigração e refúgio, inscritos no Fundo de Cultura e Extensão Universitária no Instituto de Psicologia da Universidade de São Paulo, em parceria com a Pós-graduação de Psicologia Social da PUC-SP. O projeto teve seu início em 2004, a partir do pós-doutorado História, clínica e a cultura em Psicanálise, de Taeco Toma Carignato. Trabalhamos com várias instituições voltadas ao acolhimento dessas pessoas e, no decorrer dos anos, solidificamos uma parceria com a Casa do Migrante, albergue que acolhe migrantes do Brasil, imigrantes do Cone Sul e africanos que pleiteiam a condição de refugiados. É uma instituição gerenciada por padres scalabrinianos, voltados para essa temática, que atuam em conjunto com a Pastoral do Migrante, na cidade de São Paulo.

Esse trabalho se desdobra a partir da experiência de sujeitos afetados diretamente por fatos sociais e políticos que levam à exclusão, segregação e consequente emigração ou exílio do país de origem, e busca de refúgio em país estrangeiro. Nosso objetivo principal é estabelecer espaços de intervenção nessa população, ao gerar elaborações singulares e grupais e apontar as diferentes possibilidades de reconstituição de laços sociais, assim favorecendo os vínculos afetivos e de trabalho de modo a possibilitar revisar e elaborar formas de viver os "novos contextos".

Sob a perspectiva psicanalítica, os laços sociais remetem à condição constitutiva do homem e da civilização, condição esta que inaugura a entrada do homem na linguagem e na cultura e que o insere simultaneamente no jogo relacional, afetivo, libidinal e também no jogo político, jurídico. Os laços sociais têm seu fundamento na linguagem, mas, a partir desse ponto, materializam-se nos modos de

\footnotetext{
* Autora correspondente: debieux@terra.com.br
}

relação em um dado tempo e lugar, pautando a construção das histórias de cada um, inserida no campo discursivo de seu tempo, e caracterizando os laços sociais como laços discursivos.

Os discursos que circulam em um dado tempo indicam os modos de pertencimento possíveis àqueles sujeitos e procuram, ideologicamente, equiparar-se ao campo simbólico da cultura e da linguagem. Dessa forma, impasses no laço social que dizem respeito ao campo da política podem desarticular os sujeitos em sua relação com a linguagem. É nessa medida que, nos casos em questão, revisando e rememorando suas histórias e acidentes de vida, é possível a elaboração do luto do exílio, a partir do qual imigrantes, migrantes, refugiados e "retornados" possam vir a constituir vínculos com a cidade.

Essa experiência nos permite observar inúmeras saídas e reorganizações criativas, com articulações entre política e desejo. Também observamos impasses relativos à angústia, à culpa e à superação das violências, à potência enlouquecedora do trauma, às desorganizações subjetivas e à errância sem fim de alguns desses sujeitos. Formulamos coordenadas da clínica do traumático e as estratégias e dispositivos clínico-políticos desenvolvidos na abordagem desses sujeitos.

Além da Extensão universitária em parcerias com várias áreas, desenvolvemos cursos, realizamos eventos que visam dar visibilidade a esse fenômeno social em sua faceta contemporânea e produzimos desenvolvimentos teóricos sobre o tema, sendo uma importante área para a realização de pesquisas dentro da Psicologia.

Este número foi composto por apresentações em cursos e palestras realizadas no Programa de Pósgraduação da Psicologia da USP, assim como em dois eventos destinados ao público em geral. Fomos curadores do evento Imigrantes e refugiados: deslocamentos em um mundo em crise, realizado no Centro Cultural do Banco do Brasil, de maio a agosto de 2012. Parte de suas palestras foi publicada no livro Política e desejo: desafios e perspectivas no campo da imigração e do refúgio (Rosa, Carignato, \& Alencar, 2013). Outro evento, Desigualdades, deslocamentos e políticas públicas na imigração e refúgio, foi realizado em parceria com o Memorial da América Latina em 2013. Ambos os eventos contaram com palestrantes, 
pesquisadores importantes no contexto nacional e internacional, e reuniram psicanalistas, sociólogos, filósofos, profissionais da área de saúde pública e militantes de direitos humanos para debater os deslocamentos humanos e seus desdobramentos políticos, culturais e subjetivos. Foram abordadas sob o ponto de vista clínico, político e cultural as políticas que levam em conta os direitos e as vicissitudes dos imigrantes e dos refugiados, bem como os desafios e os impasses de sua integração na sociedade brasileira.

Este número temático será contemplado com oito artigos vindos dos debates citados. Alguns debatem a questão pela via da política e outros abordam a face clínica-política da questão.

O artigo de Carmem Lussi, da Organização Internacional para as Migrações (OIM), intitulado Politicas públicas e desigualdades na migração e refúgio, analisa como desafio para as políticas públicas brasileiras o tema da alteridade de migrantes e refugiados quando esta é vivida ou interpretada como diferença que discrimina, exclui ou criminaliza, transformando sua riqueza em desigualdade que produz e reproduz vulnerabilidades. $\mathrm{O}$ texto debate as contribuições ao tema do Relatório Mundial de 2013 da OIM seguido de reflexões sobre a criminalização das migrações. A conclusão sublinha a relevância do reconhecimento dos sujeitos migrantes e refugiados como protagonistas na formulação das políticas migratórias que queiram ter a marca da equidade.

$\mathrm{O}$ enlace entre Oriente e Ocidente em relação às questões sociais e geopolíticas do século XX e início do XXI é abordado no artigo Migrantes, pós-colonialismo e fundamentalismo de Soraya S. Smaili. Depois de uma breve análise sobre o colonialismo europeu e a sua construção em relação ao mundo árabe e islâmico, os fluxos migratórios para os países centrais e a origem do fundamentalismo no Ocidente, a autora aborda a base do aumento das tensões da atualidade e a origem dos estereótipos para indicar os possíveis enlaces e reforçar a necessidade do conhecimento do outro para que o diálogo e a coexistência estejam no centro do debate.

No artigo $O$ outro: análise crítica de discursos sobre imigração e gênero, Ilana Mountian e Miriam Debieux Rosa propõem o debate sobre o desenvolvimento teórico do Outro na Psicanálise e nos estudos críticos feministas e antirracistas e analisam imaginários sociais acerca da imigração, considerando os discursos sobre raça e gênero sexual. Nos casos apresentados, nota-se que o processo de imigração muitas vezes não é levado em consideração na relação com o imigrante, o que pode naturalizar as diferenças sociais como traços individuais patologizados, quando não criminalizados. Uma série de imaginários sociais são ressaltados e vividos nas relações entre o eu e o outro (imigrante). Embora com suas especificidades, pode-se ressaltar como este aparece muitas vezes relacionado a uma imagem estática e sem modulação, fetichizado nas posições de vítima, ameaça e exótico reiteradas no discurso.

O artigo Del campo a la periferia de la ciudad, la omnipresente sombra de la violencia, escrito por Myriam
Ocampo Prado e sua equipe, trata de camponeses migrantes na Colômbia, provenientes da região de Catatumbo, caso paradigmático de um processo de desterritorialização e reterritorializaçao de uma comunidade nesse país. $\mathrm{O}$ estudo de caso relata como o conflito armado, que tem como cenário de confrontação as áreas rurais do país, tem consequências nas periferias urbanas das cidades colombianas, nos bairros onde moram os agricultores deslocados. $\mathrm{O}$ texto aborda a transformação radical da territorialidade rural e a iminente necessidade de estabelecer processos de reterritorialização no encontro com a população urbana. Instala-se um cenário de disputa pelos recursos entre os novos migrantes urbanos tratados como vítimas e os antigos residentes, migrantes de épocas anteriores que igualmente demandam assistência do Estado.

Seguem artigos voltados ao atendimento em saúde em geral e saúde mental. Em Impasses no atendimento e assistência do migrante e refugiados na saúde e saúde mental, Felicia Knobloch afirma que várias são as problemáticas envolvidas nas questões da assistência e atendimento à saúde dos migrantes e refugiados. Por um lado, a saúde dos migrantes sempre foi capítulo obrigatório nos manuais de higiene pública e, por outro, as questões de saúde têm surgido como porta de entrada aos direitos humanos desse grupo. Dessa forma, saúde torna-se um dispositivo de reconhecimento do migrante. Entretanto, a forma pela qual se entende a assistência a esse grupo pode levar a um "desreconhecimento" do sujeito. Um dos impasses que surgem no campo da saúde é quando se naturaliza a experiência migratória como um fator de risco que leva à patologia psíquica, sob o risco da medicalização da experiência migratória e um controle farmacológico de problemas que, na realidade, podem ser de ordem social, política ou econômica. A psicanalista apresenta o que considera os desafios no campo da saúde em relação à formação de trabalhadores da saúde: a importância de dar suporte ao encontro e de não estereotipar a condição de migrante ou de refugiado, cuidar para não silenciar a singularidade do sujeito, compreender a representação da saúde e da doença dentro do contexto de origem do sujeito, e considerar as especificidades do momento atual de vida do sujeito como elementos que devem ser levados em conta no atendimento - tanto à saúde em geral quanto à saúde mental - dos migrantes e refugiados.

A experiência francesa nos é fornecida pelos dois textos seguintes. Em Do relatório ao relato, da alienação ao sujeito: a experiência de uma prática clínica com refugiados numa instituição de saúde, Marie-C. Saglio-Yatzimirsky evidencia a especificidade e os limites de uma consulta hospitalar a sujeitos refugiados, atendidos por distúrbios psicotraumáticos. Trauma e cultura estão no cerne desse trabalho psicoterápico, uma vez que os atendimentos são atravessados pela situação sociopolítica desses pacientes, mas também por parte da representação do sujeito requerente de refúgio, impregnada na estrutura administrativa tributária de uma concepção ocidental da ajuda médica e psíquica destinada a tratar a "desorientação" do sujeito migrante. 
O artigo Psicoterapia transcultural da migração de Marie Rose Moro discute sobre o tratamento psicológico em situação transcultural, ressaltando a importância de se considerar um número de questões específicas da imigração. Apresenta também as bases da clínica transcultural com sujeitos imigrantes, expondo os elementos principais necessários à adaptação do enquadramento terapêutico, bem como seus princípios, suas indicações e as limitações da consulta clínica transcultural.

Ademir Pacelli Ferreira versa sobre a questão da irrupção de uma crise psicótica em um migrante brasileiro, recém-chegado do interior, defrontado com a diferença social e cultural de um grande centro urbano como a cidade do Rio de Janeiro. Em Migração, rupturas psíquicas e espaços terapêuticos, analisa a experiência psicótica correlacionada ao lugar que o migrante do interior ocupa no espaço das grandes cidades, onde o sentimento de estranheza vivenciado pelo sujeito traz as marcas do lugar de deslocado que este ocupa nesse espaço. Ilustra a exposição com elementos da clínica, demonstrando a duplicação do sujeito ao ser tomado pelo Outro da psicose e o seu desdobramento resolutivo, por meio da acolhida e do acompanhamento terapêutico. Aspectos do modelo assistencial tradicional são assinalados para se contraporem à experiência aqui analisada, que valoriza a importância do acolhimento ao sujeito em sua diferença, tanto em relação à sua origem sociocultural quanto à sua condição psicótica. Afirma os espaços de ação, linguagem e sentido como favorecedores da recomposição do posicionamento subjetivo e o resgate de referências identitárias, facilitando a ressignificação da história e do próprio drama do sujeito.

Esses artigos apresentam importantes contribuições ao debate da clínica e da política da imigração, assim como aos desenvolvimentos teóricos da Psicanálise e da Psicologia, trazendo à tona diversos aspectos da clínica com imigrantes e promovendo argumentações que ressaltam a importância de se considerar aspectos políticos e sociais na clínica.

\section{Referências}

Rosa, M. D., Carignato, T. T., \& Alencar, S. L. (Orgs.). (2003). Política e desejo: desafios e perspectivas no campo da imigração e do refúgio. São Paulo, SP: Max Limonad. 